\title{
O DOCENTE UNIVERSITÁRIO COMO PROFISSIONAL PESQUISADOR DE SUA PRÓPRIA PRÁTICA
}

THE UNIVERSITY PROFESSOR AS A PROFESSIONAL RESEARCHER OF HIS OWN PRACTICE

EL DOCENTE UNIVERSITARIO COMO PROFESIONAL INVESTIGADOR DE SU PROPIA PRÁCTICA

Altair Alberto Fávero

Doutor em Educação pela UFRGS. Docente do Programa de Pós-Graduação em Educação da UPF.

Darciel Pasinato

Mestrando em Educação pela UFP.

Pós-Graduação em Educação

Universidade de Passo Fundo (UPF)

Passo Fundo - RS - Brasil

Endereço:

UPF - Campus I

Rodovia BR 285 - Km 292

São José - Passo Fundo - RS

CEP: $99052-900$

E-mails:

altairfavero@gmail.com

darcielpasinato@bol.com.br

RESUMO

O presente artigo é resultado parcial de uma pesquisa bibliográfica e constitui uma reflexão teórica sobre a formação do professor universitário. Para tanto, trabalha com o pressuposto de que a formação do educador é um dos fatores determinantes para que haja melhorias no processo ensino-aprendizagem e na formação do cidadão consciente e emancipado. Acreditamos que um dos caminhos mais promissores para que aconteça esse processo formativo é tornar o professor universitário um profissional pesquisador da própria prática docente. Nosso objetivo é realizar um processo reflexivo sobre esse processo, nos servindo, para tal, de alguns autores que possam indicar possibilidades para sua concretização. 0 artigo está estruturado em três tópicos. O primeiro trata sobre o problema da relação pedagógica entre professor e aluno e a necessidade de repensar os processos de aprendizagem. Na sequência, o texto aborda a problemática da carreira do docente universitário e, por fim, a terceira parte discute a possibilidade do professor do ensino superior ser um pesquisador de sua própria prática docente. Como conclusão, o artigo ressalta a urgência para que nas instituições de Educação Superior ocorram processos de formação do professor pesquisador para além dos programas de pós-graduação stricto senso. O artigo é produção parcial do projeto de pesquisa "A improvisação docente no contexto da expansão da Educação superior: o problema da identidade docente".

PALAVRAS-CHAVE: Docente investigador. Educação superior. Professor universitário.

ABSTRACT

This article, which is the partial result of a literature review, consists of a theoretical reflection on the formation of the university professor. It starts with the premise that the educator's training is one of the 
determining factors for improvement in the teaching-learning process, and in the formation of an aware and emancipated citizen. We believe that one of the most promising ways for this formative process to occur is to transform the university professor into a professional researcher of his own teaching practice. Our objective is to offer a reflection on this process, drawing on some authors that indicate possibilities for this realization. This aims of this article are three-fold. First, it deals with the problem of the relationship between the professor and the student, and the need to rethink the learning processes. Second, it addresses a problem regarding the career of the higher education professor. Finally, the third part discusses the possibility of a higher education professor being a researcher of his own teaching practice. In conclusion, this article highlights the urgent need for the processes of formation of research professors in Higher Education institutions, besides stricto sensu graduate programs. This article is part of a wider research project entitled "Teaching improvisation in the context of expansion of Higher Education: the problem of teaching identity".

KEY WORDS: Research professor. Higher education. University professor.

\section{RESUMEN}

El presente artículo es resultado parcial de una investigación bibliográfica y constituye una reflexión teórica sobre la formación del profesor universitario. Para ello trabaja con la presuposición de que la formación del educador es uno de los factores determinantes para que haya mejorías en el proceso enseñanzaaprendizaje y en la formación de un ciudadano consciente y emancipado. Creemos que uno de los caminos más promisorios para que se realice este proceso formativo es hacer del profesor universitario un profesional investigador de la propia práctica docente. Nuestro objetivo es realizar un proceso reflexivo sobre ese proceso, utilizando para ello algunos autores que puedan indicar posibilidades para su concreción. El artículo está estructurado en tres tópicos. El primero trata sobre el problema de la relación pedagógica entre profesor y alumno y la necesidad de repensar los procesos de aprendizaje. A continuación, el texto aborda la problemática de la carrera del docente universitario y, por último, la tercera parte discute la posibilidad de que el profesor de enseñanza superior sea un investigador de su propia práctica docente. Como conclusión, el artigo destaca la urgencia de que en las instituciones de Educación Superior ocurran procesos de formación del profesor investigador, más allá de los programas de posgrado stricto senso. El artículo es producción parcial del proyecto de investigación "La improvisación docente en el contexto de la expansión de la Educación Superior: el problema de la identidad docente".

PALABRAS CLAVE: Docente investigador. Educación superior. Profesor universitario.

\section{INTRODUÇÃO}

O processo de desenvolvimento e modernização da sociedade inclui modelos de participação e de compreensão que transformam velhas estruturas em formas qualificadas de atuação e vivência. Há enormes desafios a serem enfrentados em todos os setores da sociedade, com especial atenção à questão da formação de recursos humanos. Assim, a escola e a universidade passam a ter uma responsabilidade maior com os currículos, com as ações políticas, pedagógicas e culturais. A educação está envolvida em diversos problemas, tais como evasão escolar, aprendizagem deficiente, baixa qualificação dos docentes, entre outros. A formação docente torna-se complexa em sua efetivação, pois tem o compromisso de preparar o sujeito para ser profissional e cidadão numa sociedade permeada de problemas de todas as ordens.

A figura do professor sempre ocupou um papel central na educação. Na pedagogia tradicional o professor reinou soberano como o centro do processo educativo. Já no século XX defendia-se postura que ainda tem validade neste início do século XXI, que o professor se constitui na prática, que é necessário prestar atenção à aprendizagem, e que os alunos possuem um papel imprescindível no processo educativo. O professor passou a ser cada vez mais um executante, e na crítica de alguns 
autores (FÁVERO; TONIETO, 2010; GIROUX, 2007; MISUKAMI, 1986; PÉREZ GÓMEZ, 1995) um profissional da educação que desenvolve sua prática numa perspectiva mais instrumental. Não são poucas as situações em que vemos professores improvisando seu trabalho docente em sala de aula, por não terem tempo de preparar adequadamente suas aulas, ou por acreditarem que a prática docente é a simples execução de um roteiro de atividades. Cria-se, com isso, a imagem de que os professores são incompetentes no que concerne ao ensino, e a questão da formação deficitária aparece de forma contundente.

A partir da relação teoria/prática o saber dos professores ou o saber ensinar tem como fundamento modelos de ação, considerados como representações elaboradas e veiculadas pelos professores a respeito da natureza de sua prática. "No contexto das múltiplas narrativas educacionais em que o professor precisa pensar a sua profissão", destaca Marília Morosini (2008, p.108), "um elemento decisivo na figura do professor como responsável no processo educativo é conferido à autonomia profissional, variável segundo o modelo de professor predominante". As considerações de Morosini nos alertam para o fato de que não podemos tratar a identidade do professor como um personagem genérico, universal, igual em qualquer circunstância. A autonomia profissional do professor se dá em consonância com a forma como ele articula sua própria formação e sua prática educativa.

Para Zabalza (2004, p. 111), "ensinar é uma tarefa complexa na medida em que exige conhecimento consistente acerca da disciplina ou das suas atividades". Com isso, ressalta-se a necessidade de evitar certas simplificações frequentemente expressadas pelo senso comum, tais como "ser professor é algo fácil", "para dar aula no ensino superior basta dominar o conteúdo", "a experiência ensina dar aula". Sobre esse aspecto tem razão Tauchen \& Fávero (2011, p.411), quando dizem que "o professor, além de conhecer os conteúdos de ensino, precisa ser capaz de analisar e resolver problemas, saber transformar um conhecimento científico em conhecimento ensinável [...]". Para que o professor possa dar conta dessas tarefas, ele necessita selecionar estratégias metodológicas adequadas que facilitem a aprendizagem, organizar os saberes que possibilitem o acompanhamento dos estudantes, regular os processos de aprendizagem por meio da avaliação, entre outros saberes. São exigências intelectuais que ultrapassam o mero domínio de conteúdos conceituais ou o saber científico específico. O ensino é uma atividade interativa realizada com determinados sujeitos e, por isso, demanda a reprofissionalização do docente (ZABALZA, 2004).

O critério de eficiência do trabalho do professor possui relação direta com a eficiência da aprendizagem do seu aluno, ou seja, sua eficiência como professor depende dos recursos que utiliza para conseguir maiores ou menores resultados de aprendizagem dos alunos. Por isso, seu modo de agir em sala de aula, mais do que suas características de personalidade, é elemento imprescindível para uma adequada aprendizagem dos alunos.

Compreendendo a tarefa docente na perspectiva da aprendizagem, a pesquisa passa a ter um papel de extrema importância para a formação e para o trabalho do professor. Tanto num aspecto como no outro, ela ainda constitui um desafio para os estudiosos do tema. Sabe-se que a formação teórica do professor, com aulas de metodologia, não é suficiente. Porém, sabe-se que as pequenas pesquisas, cabíveis dentro dos limites dos cursos de formação, em geral não passam de arremedos artificiais, que não têm possibilidade de preencher de modo satisfatório quase nenhum dos requisitos da formação do pesquisador.

Aprender e ensinar constituem duas atividades muito próximas da experiência de qualquer ser humano: aprende-se quando se introduzem alterações na forma de pensar e agir, e ensina-se quando se partilha com o outro, ou em grupo, a experiência e os saberes que se vai acumulando. $O$ ensino, por sua vez, confunde-se, no seu sentido mais lato, com a socialização e pode conceber-se como uma atividade comunicativa. Nesse sentido, ensina-se quando se partilha, se orienta ou se informa. Refletir sobre aprendizagem é indagar-se sobre a natureza e a variedade de aprendizagens a que se está exposto, sobre as variáveis e os mecanismos que interferem no processo, bem como sobre as propostas que pensadores e teóricos encontram para explicitar e incrementar. A aprendizagem é um processo natural inerente à condição do ser vivo e à necessidade de sobrevivência.

O presente artigo tem como propósito abordar o desafio de tornar o docente universitário um profissional pesquisador da própria prática docente e como principal objetivo indicar possibilidades para que possa tornar o exercício da docência um objeto de pesquisa. Nessa perspectiva, o artigo se estrutura em três tópicos. O primeiro trata sobre o problema da relação pedagógica entre professor 
e aluno e a necessidade de repensar os processos de aprendizagem; na sequência, o texto aborda a problemática da carreira do docente universitário e, por fim, na última parte, discute a possibilidade do professor do ensino superior ser um pesquisador de sua própria prática docente.

\section{RELAÇÃO PEDAGÓGICA ENTRE PROFESSOR E ALUNO E A NECESSIDADE DE REPENSAR OS PROCESSOS DE APRENDIZAGEM}

A ação docente constitui o fundamento básico para a transformação socioeducativa, assim como a (re)definição de novos paradigmas para a ação propicia a construção de soluções para os problemas do cotidiano que venham a ser enfrentados na sala de aula. A ação docente em sala de aula é resultado da formação e das convicções do professor, ou seja, está relacionada com sua trajetória de vida, seu processo formativo acadêmico e sua forma de ver o mundo, bem como com o conhecimento, a sociedade e com tudo o que interfere no seu entorno social. O ato de replanejar emerge da experiência profissional e das concepções que o educador detém sobre os pressupostos teóricos da educação. O professor está constantemente em conflito, está à procura do dever-ser, tentando encontrar sustentação para a sua ação docente, de modo que a educação possa ser um dos elementos capazes de tornar o homem um ser ético-crítico, comprometido consigo e com um projeto de sociedade mais justa, humana e igualitária.

Para manter coerência entre aquilo que diz e aquilo que faz, o professor necessita de uma sólida formação intelectual e humana. Necessita apoiar sua ação em valores de forma que os educandos acreditem que a maneira como o educador está desempenhando suas funções serve-Ihes de parâmetro para com ele conviver e trabalhar. De acordo com Sartori (1998, p. 42), "o ensino considerado sob sua ótica do processo educativo lida com os conhecimentos puros, com a natureza do conhecimento, garantindo que ocorra a passagem da ciência para a prática". O momento é de ação e de superação dos atos que se revelaram ineficientes e ineficazes ao longo da história da educação. Os contrastes sociais podem ser usados para iniciar um processo de leitura crítica da realidade, buscando, a partir disso, empreender ações no sentido de transformar essa realidade.

A grande preocupação no ensino superior é com o próprio ensino, no seu sentido mais comum: o professor entra em sala para transmitir aos alunos informações e experiências consolidadas para ele por meio de seus estudos e atividades profissionais, esperando que o aprendiz as retenha, as absorva e as reproduza por ocasião dos exames e das provas avaliativas. Esses professores são, primeiramente, educadores, que assumem que a aprendizagem se constrói num relacionamento interpessoal dos alunos com outros colegas, dos alunos com outros profissionais de sua área, dos alunos com diferentes locais onde deverão exercer sua atividade. Por fim, constituem um corpo docente que entende que a aprendizagem se faz com colaboração, participação dos alunos e com respeito mútuo e trabalhos em conjunto.

No primeiro encontro com os alunos, é de extrema importância iniciar o contato deixando claro que o sucesso daquela disciplina vai depender de um trabalho em equipe entre professor e alunos, de parceria e de corresponsabilidade. É relevante, também, evidenciar que tal relação irá começar naquele instante, quando o grupo vai procurar se conhecer melhor e se manifestar sobre quais são suas expectativas sobre a disciplina, revelando o que já ouviram falar sobre ela, que comentários ouviram de colegas, o que acreditam que vão estudar e para que julgam servir aquela disciplina. Estabelecido tal processo, deve-se perguntar aos alunos quais os objetivos têm-se com essa atividade. Segundo Masetto (2005, p. 91), deve-se "criar oportunidade para um início de integração entre membros da turma visando à formação de um grupo de trabalho e envolver os alunos com a disciplina e procurar que eles se interessem por ela". Vamos gastar tempo com isso, mas ganharemos os alunos se esses se mostrarem motivados para aprender o que se pretende que aprendam.

A finalidade de todo o ensino é permitir que o aluno compreenda e capte a estrutura da matéria em estudo para poder relacionar de forma significativa com outros saberes. As aprendizagens que hoje são propostas, a diversos níveis do ensino, são formulações de descobertas, relatos e elaborações que levaram anos a constituírem-se como corpo de conhecimentos. Compete ao aluno orientar a sua vontade de aprender, tendo em conta as suas potencialidades e aptidões, concentrando a sua atenção e os seus esforços em tarefas fundamentais, de modo a construir a sua estrutura do saber fazer, de forma organizada, clara e significativa. No dizer de Sousa (2005, p. 59), "cabe 
ao professor, como mediador entre a comunidade, os saberes e o aluno, dominar a estrutura dos conteúdos, estar atento à estrutura dos conteúdos, estar atento à estrutura do sujeito, ter em conta as expectativas da comunidade em que se integra e escolher a forma mais adequada para a comunicação pedagógica".

Questões novas passam a ocupar lugar comum: quem é o docente universitário? Ele está preparado para acompanhar as mudanças do terceiro milênio? A complexidade da resposta pode ser vista de diversos ângulos. Exige-se, cada vez mais, capacitação permanente nos cursos de pósgraduação da área de conhecimento. Mas o docente está preparado didaticamente para o exercício acadêmico? Por premissa, considerando o tipo de graduação realizada, encontram-se, exercendo a docência universitária, professores com formação didática obtida em cursos de licenciatura; outros, que trazem sua experiência profissional para a sala de aula; e outros, ainda, sem experiência profissional ou didática, oriundos de curso de especialização e/ou stricto sensu. O fator definidor da seleção de professores, até então, era a competência científica.

O final da década de 1990, refletindo orientações internacionais, é marcado pela edição de inúmeras normatizações que dão um caráter determinante às relações Estado/Universidade. Atualmente, a principal legislação que regulamenta de modo geral a educação no Brasil é a LDB (Lei no 9.394), sancionada pelo Presidente da República (Fernando Henrique Cardoso) em 20 de dezembro de 1996. Uma das principais características dessa legislação sobre quem é o professor universitário, no âmbito de sua formação didática, é o silêncio. Enquanto nos outros níveis de ensino o professor é bem identificado, no ensino superior parte-se do princípio de que sua competência advém do domínio da área de conhecimento na qual atua. Em síntese, o professor universitário sofre uma marcante pressão, advinda da legislação, imposta pela instituição e buscada por ele, para sua qualificação de desempenho, no qual o didático passa a ocupar um papel de destaque.

A definição de Universidade implica a sua compreensão como uma instituição que necessita desenvolver ensino, pesquisa e extensão, ter autonomia didática, administrativa e financeira e congregar um corpo docente com titulação acadêmica significativa de mestrado e doutorado. Conforme o tipo de instituição de ensino superior em que o professor atua, sua docência sofrerá diferentes pressões. Se atua num grupo de pesquisa em uma universidade, provavelmente sua visão de docência terá um forte condicionante de investigação. Já se atua numa instituição isolada, num centro universitário, sua docência terá um forte condicionante de ensino sem pesquisa, ou, quando muito, do ensino com pesquisa.

Entretanto, é importante ressaltar que, mesmo nas instituições universitárias, a afirmação de que todos os docentes tenham a sua atividade relacionada à pesquisa não é verdadeira, conforme aponta Morosini (2000, p.19):

\footnotetext{
A pedagogia universitária no Brasil é exercida por professores que não têm uma identidade única. Suas características são extremamente complexas, como complexo e variado é o sistema de educação superior brasileiro: temos instituições públicas e privadas, universidades e nãouniversidades, em cinco regiões da Federação de características étnicas, sociais e econômicas diferentes.
}

O ponto de partida para a construção discursiva é a constatação de que o professor de ensino superior é parte de uma comunidade de conhecimento. Resumindo, pode-se dizer que o professor de ensino superior trabalha em diferentes tipos de instituições, desenvolve nelas atividades que se qualificam de diferentes formas, enfrenta tensões das mais variadas, seja com os pares da mesma ou de diferentes áreas, é um profissional não necessariamente somente da universidade e mostra diferentes relações com o conhecimento, seja para produzi-lo ou para disseminá-lo.

A formação docente do professor universitário caracteriza-se pela diversidade, pela pluralidade de opções, pelos caminhos, interesses e pelas alternativas e tensões. Não surpreende que, nesse contexto, o processo formativo apresente inúmeras alternativas. No que concerne a cursos formais e certificados, uma das mais procuradas alternativas é a opção por cursos de mestrado que oportunizem o aprofundamento na área específica e o atendimento a alguma disciplina ligada à pedagogia universitária. Outra alternativa procurada é a matrícula em algum mestrado na área da educação, muitas vezes com dissertações que, de algum modo, contemplam a área específica de onde se originam (engenharia, direito, medicina, enfermagem, farmácia, administração, etc.). 
A resposta das universidades ao avanço do conhecimento é, por vezes, mais lenta do que se gostaria que fosse. Atualmente, o (re)credenciamento das universidades está condicionado à comprovação de produtividade acadêmica, de dedicação de um percentual de docentes em regime de tempo integral, e de diversos outros requisitos que são avaliados por ocasião da supervisão do Ministério da Educação por meio de seus organismos de fiscalização. Surge o questionamento: se não fossem esses mecanismos de controle, será que existiria por parte das instituições a vontade política de concretizar ações que viabilizassem a pesquisa? Teriam as universidades políticas de acesso à pós-graduação planos institucionais de qualificação docente, estímulos pela via de bolsas de iniciação científica e assim por diante? Assim como são encontrados exemplos que mostram a crescente consciência quanto à necessidade de pesquisa, outros tantos levam a questioná-la. A pesquisa técnico-científica seria um fator gerador de desenvolvimento. E não só isso: o próprio conhecimento contribuiria para o surgimento de condições que consolidariam a pesquisa nas universidades e nas instituições de pesquisa. A consciência dos elos que existem com a pesquisa é decisiva para que sejam abertas maiores possibilidades de seu uso intencional na formação do professor.

Um dos desafios é o de ampliar o reduzido campo de atuação do professor como agente histórico e não omitir a fugacidade dos conteúdos numa sociedade em constante mudança. Nesse ponto é que entra a pesquisa. Como trabalho conjunto entre professor e aluno, que tem em mira a busca de soluções para os problemas novos e significativos, a pesquisa seria um modo de lidar com a questão do conhecimento. Pela pesquisa, o professor universitário teria condições de lidar com problemas dessa sociedade em bases mais sólidas, que melhorariam o nível de suas decisões técnicas e políticas. Essa constatação justifica um maior espaço para a pesquisa no processo de formação do professor. "O processo de pesquisa interliga pessoas, instituições e comunidade. Como a universidade é um serviço público, porque responde às necessidades da comunidade, e como a produção do conhecimento tem significado social, a pesquisa é um dos serviços da universidade" (FRANCO, 2000, p. 67).

As práticas do docente universitário se veem afetadas também pelos mesmos paradigmas, que estão mudando a produção do conhecimento e recontextualizando o discurso pedagógico, e produzindo uma universidade enfraquecida. Cabe perguntar se estamos, também, como elas, produzindo o docente atenuado, enfraquecido, cuja formação pedagógica se sustenta na alienação não só da missão das universidades contemporâneas como também do conhecimento e dos seus paradigmas. Conforme ressaltam Leite et al. (2008, p. 51):

Longe de ser um intelectual dono da verdade, acima de seu tempo e patrono dos movimentos sociais, o docente universitário, como um intelectual público, está imerso em posições ideológicas e em contextos particulares, tem uma história de vida, e portanto, não pode desempenhar um papel previamente definido, um script estandardizado de falas e movimentos.

Em um dos capítulos do livro Educar o educador, Fávero e Tonieto (2010) analisam a formação docente com base na abordagem metodológica da história de vida, com a finalidade de ajudar a enfrentar e, talvez, a superar a dicotomia entre teoria e prática, além de apontar uma instigante proposta de formação continuada. Para Fávero e Tonieto (p.19), "são os referenciais teóricos e metodológicos que dão aporte para problematizar e ressignificar o processo de construção da identidade profissional docente, tentando captá-la como movimento que se inscreve nas suas trajetórias profissional e pessoal, uma vez que ambas fazem parte do processo formativo de um mesmo sujeito, o professor". Na história de vida de cada professor há, no entendimento dos autores (p.20), uma "mútua influência" das dimensões pessoal e profissional que constituem o processo formativo de cada professor e por isso, ao se tratar sobre a formação docente, deve haver uma "articulação entre a dimensão particular das contingências das histórias de vida e a dimensão universal dos princípios teóricos que fundamentam a própria formação".

Conforme ressaltam Fávero e Tonieto (2010, p.75, grifo dos autores), "toda prática docente é carregada de intencionalidade, seja ela refletida ou não. Toda prática docente busca intervir na e contribuir para a formação de outros. Desse modo, de acordo com a intencionalidade que se tem são pensadas ações, intervenções e contribuições". Se indagarmos sobre qual a intencionalidade da prática docente na educação superior, poderíamos dizer que uma das principais intenções é "interferir e contribuir para formação de futuros profissionais cidadãos". Parece que isso seria relativamente tranquilo na concepção da maioria dos docentes universitários, no entanto, a pergunta que poderia ser colocada é: "de que forma essa intencionalidade se efetiva na docência e nas aulas de tais professores?". 
Em seu texto "Docência universitária: repensando a aula", Marcos Masetto (2005, p.107) ressalta que "por trás do modo como geralmente acontecem as aulas na universidade, há um paradigma de ensino consolidado e estruturado há várias décadas e que sustenta a docência universitária", o qual define as práticas pedagógicas de cada professor. Conforme a abordagem de Masetto (2005), há dois modos distintos de compreender a ação docente no ensino superior: o paradigma do ensino e o paradigma da aprendizagem. O primeiro tem como eixo central, como o próprio nome expressa, "o ensino de conteúdos" e consiste na ideia de que a tarefa primordial do professor é "transmitir aos alunos um conjunto de informações que possui um fim em si mesmo". Por sua vez, o paradigma da aprendizagem parte do pressuposto de que a pergunta que deve orientar a ação docente deve ser a seguinte: "O que meus alunos precisam aprender para que se tornem cidadãos profissionais competentes na sociedade contemporânea?" (MASETTO, 1998, p.12). Essa mudança da pergunta que mobiliza a ação docente do professor implica um deslocamento de seu próprio trabalho e da maneira como ministra suas aulas. Os conteúdos deixam de ser mera informação que instrumentaliza os futuros profissionais e passam a se tornar parte integrante do processo de "desenvolvimento da pessoa", ou seja, a formação de um profissional cidadão que necessita, além de conteúdos, de "habilidades humanas e profissionais, capacidades intelectuais, valores e atitudes a serem desenvolvidos" (FÁVERO; TONIETO, 2010, p.77-78).

A sala de aula, na perspectiva da aprendizagem, deixa de ser um espaço físico dedicado somente ao ensino, e passa a ser considerada como um lugar "de encontro dos sujeitos" onde ocorre o processo de problematização, socialização e construção do conhecimento, passando a ser dessa forma uma aprendizagem significativa. Como ressaltam Fávero e Tonieto (2010, p.81), "a aprendizagem é significativa quando o professor, além de expor o conteúdo, explica a matéria e partilha experiências profissionais, também incentiva o desenvolvimento do aluno, está atendo aos seus progressos e corrige quando necessário".

Talvez esse desafio de passar da ênfase do paradigma do ensino para a ênfase do paradigma da aprendizagem pode se constituir como algo complexo e difícil de ser realizado pela grande maioria dos professores universitários, devido a um conjunto de mitos e de condicionantes que pesam sobre seu cotidiano. No entanto, as instituições necessitam urgentemente pensar projetos de formação que teorizem sobre essa perspectiva para que a universidade não perca o "bonde da história" nos desafios que se desenham neste início de século. Dentre esses desafios está o de constituir um docente pesquisador. Antes de tratar desse aspecto, abordaremos no próximo tópico a problemática da carreira do docente universitário, para, em seguida, voltar nosso olhar sobre o docente investigador.

\section{O PROBLEMA DA CARREIRA DO DOCENTE UNIVERSITÁRIO}

Preliminarmente, para que fique clara a linha de raciocínio que se pretende seguir, importante distinguir carreira universitária de qualificação universitária, tema sobre o qual há, na sistemática atual da universidade brasileira, variações entre as instituições públicas e as particulares. Destaca-se a Universidade de São Paulo. Nela há seis degraus: auxiliar de ensino, professor assistente, professor doutor, professor livre-docente, professor adjunto e professor titular. Os cargos iniciais e os finais de carreira, por força de lei, são preenchidos por concursos públicos de títulos e provas. As demais posições são funções gratificadas. O primeiro degrau, o de auxiliar de ensino, é considerado como estágio probatório não integrado à carreira. Esse cargo, fora do quadro, é preenchido por contrato proposto pelo conselho do departamento. O cargo inicial da carreira é o de professor assistente. Os demais níveis são funções.

A qualificação universitária é aberta e não exige que o interessado pertença ao quadro permanente. Os títulos de mestre, de doutor e de livre-docente poderão ser conquistados por pessoas estranhas ao quadro da universidade. O profissional que vive do exercício de sua profissão pode querer aprimorar seus conhecimentos e encontrará, dentro da universidade, essa oportunidade que Ihe dará o comprovante de sua qualificação, aumentando-Ihe os horizontes e o prestígio entre os seus pares. A carreira universitária é a sequência de degraus que o elemento do corpo docente de escola superior deverá seguir na dependência de sua qualificação universitária. A interdependência entre carreira e qualificação, vinculada ao apoio da primeira sobre a segunda, é a garantia da valorização progressiva do corpo docente da universidade. O progredir na carreira, decorrendo da qualificação 
superior, garante aprimoramento constante do seu corpo docente. A exigência de íntima relação entre ensino e pesquisa garante a solidez do processo.

Há consenso de que a emancipação universitária dá-se em nível de doutorado. Até essa altura, o docente deve ter orientador. Uma vez conquistado esse título, ele poderá então ser orientador de outros iniciantes e integrar comissões examinadoras de concursos de acesso à carreira de docente até seu próprio nível. Depois dessa qualificação, o docente está em condições de candidatar-se à livredocência. Conquistando o título de livre-docente, terá credenciais para assumir responsabilidades de cursos dentro ou fora da unidade ou da própria universidade. No dizer de Moraes, "a pós-graduação foi criada e implantada visando exclusivamente à formação de pessoal docente de nível superior" (p. 28, 1986). Acredita-se ser a pós-graduação a esperança para o ensino superior do Brasil, entretanto, o seu êxito dependerá de uma revisão imediata. Ainda será necessária a periódica reavaliação do sistema para que essa constante adaptação possa, em tempo útil, atender às necessidades reais do país.

A elaboração do curriculum vitae é uma das vias com a qual se depara o profissional que pretende seguir a carreira universitária. A universidade precisa, cada vez mais, daqueles que se dedicam ativamente e que têm visão de futuro, para conseguir encontrar métodos diferentes dos convencionais para atender à constante transformação socioeconômica pela qual o mundo passa na contemporaneidade. O professor universitário deve aceitar que a educação é processo permanente e que ela deve dar consciência do poder e da limitação ao jovem para que ele se prepare para o amanhã. Dentro desses conceitos e sabendo que dia a dia, nos concursos das universidades, o currículo é cada vez mais valorizado, sente-se a necessidade de sua padronização para que os confrontos sejam mais objetivos e para que cada vez menos a impressão ou a subjetividade tenham influência.

Talvez não haja dúvida de que a peça fundamental no desenvolvimento da docência universitária seja os professores. A docência universitária é uma profissão ou é o trabalho que exercemos? Qual é o eixo em torno do qual é construída a identidade profissional? A docência universitária é extremamente contraditória em relação a seus parâmetros de identidade socioprofissional. Um dos aspectos mais críticos dos professores tem sido justamente a identidade profissional indefinida. Sua preparação para a prática profissional esteve sempre orientada para o domínio científico e/ou para o exercício das atividades profissionais vinculadas a este. Com esses precedentes, é difícil, a princípio, construir uma identidade profissional vinculada à docência. Como em qualquer outro tipo de atividade profissional, os professores devem ter os conhecimentos e as habilidades exigidos a fim de poder desempenhar adequadamente as suas funções.

Usa-se o termo docência para se referir ao trabalho dos professores, mas esses desempenham, na realidade, um conjunto de funções que ultrapassa o exercício da docência. "Muitas vezes, atribuíram-se aos professores universitários três funções: o ensino (ou docência), a pesquisa e a administração (nos diversos setores institucionais: dos departamentos e faculdades às diversas comissões e à direção da universidade)" (ZABALZA, 2004, p. 109). Atualmente, novas funções agregam-se a essas: o que alguns chamaram de business (busca de financiamento, assessorias, participação como especialistas em diversas instâncias científicas, entre outras) e as relações institucionais (representação da própria universidade nas inúmeras áreas em que é exigida até a criação e a manutenção de uma ampla rede de relações com outras universidades e empresas, buscando reforçar o caráter internacional).

Um aspecto que afeta de maneira significativa a dimensão pessoal dos professores é o itinerário pessoal e profissional que os docentes seguem, condicionado pelas possibilidades de formação e promoção que são oferecidas a eles. Dessa maneira, a carreira docente apresenta-se sob duas perspectivas distintas: os estágios formais, nos quais está estruturado o processo para atingir o status profissional (carreira acadêmica), e as fases ou os momentos pessoais pelos quais um docente costuma passar até alcançar sua plenitude profissional (carreira profissional). A carreira acadêmica ou docente e os estágios profissionais, pelos quais se passa desde que se começa a trabalhar na universidade, são um fator importante tanto do ponto de vista psicológico como profissional. Somente quem possui expectativas elevadas de crescimento e melhora profissional está em condições de se esforçar para alcançá-las.

A carreira profissional faz parte da construção da identidade profissional dos docentes desde o momento em que iniciam tal processo como monitores ou assistentes até alcançarem a maturidade profissional. Um dos problemas importantes da vida profissional dos docentes é justamente o fato 
de se desconsiderar a dimensão diacrônica (evolução) do desenvolvimento profissional. Poderia se dizer que a instituição universitária considera que se formar melhor como profissional e aprender a ensinar são questões que dependem de cada professor. Os professores iniciam sua carreira como substitutos na universidade, deparando-se com diversos grupos de alunos aos quais devem explicar (fazer aprender) um número indeterminado de conteúdo, como se isso fosse uma tarefa simples, na qual eles fossem reconhecidos especialistas.

Por fim, o exercício da profissão e seu domínio não ocorrem por uma transferência direta ou divina de sabedoria. Não se pode supor que um jovem que ingressa como professor na universidade já esteja preparado para enfrentar a docência, ou, não estando, que ele mesmo tome decisões propícias a seu crescimento. Pensar que os professores universitários formam um grupo vocacional para o qual conta mais o reconhecimento e o prestígio social do que a remuneração ou as condições de trabalho é, sob qualquer hipótese, uma ingenuidade. Ao contrário disso, os últimos anos presenciaram um leque permanente de reivindicações de melhorias salariais, melhorias nas condições de trabalho e políticas claras para estabilidade e promoção dos professores.

A exposição sobre a distinção entre carreira universitária e qualificação realizada neste segundo tópico do texto nos remete a alguns questionamentos: de que forma a carreira universitária tem contribuído para melhorar a docência na educação superior? A qualificação possibilita que a educação seja um espaço de produção de professores-investigadores? Que vínculos poderiam ser estabelecidos entre a construção de professores-investigadores e a carreira universitária? Tais questionamentos nos conduzem ao assunto abordado pelo próximo tópico deste artigo, no qual será analisada a constituição do professor investigador na educação superior.

\section{PROFESSOR PESQUISADOR NA EDUCAÇÃO SUPERIOR}

Parece impossível que, imersos em um contexto de desesperança e desalento, possamos falar de professor-pesquisador. Tal profissional, além do que já foi apontado, vive rodeado de conflitos e de problemas que influenciam na sua autoestima e se traduzem num processo de empobrecimento crescente, tanto econômico quanto relativo à autonomia e ao reconhecimento social. O professor tem se tornado uma "vítima sacrificial" do sistema público de ensino, considerado por muitos um fracasso educacional, pois não consegue dar conta da capacitação dos sujeitos para as novas exigências do mundo do trabalho.

Para Stenhouse (1984), a educação é um processo cujos fins remetem a valores e princípios que determinam o modo pelo qual os professores colocam os alunos em relação com os conteúdos educacionais e avaliam os resultados desse processo. "Ao defender tais posições", na interpretação da investigadora Adriana Dickel,

Stenhouse estava se opondo frontalmente não somente a uma ideia de currículo como listagem de conteúdos a serem desenvolvidos pelo professor com seus alunos, mas também àquela que o via como um processo técnico, um 'plano racional' em que conteúdos e métodos eram concebidos como instrumentos para inculcar nos alunos conhecimentos previamente elaborados (2001, p. 50).

Stenhouse defende uma teoria da ação educativa hipotética, provisória, submetida continuamente à revisão e à crítica, desenvolvida por meio de experimentos realizados em laboratórios: uma autêntica classe a cargo de professores e não de pesquisadores. A pesquisa adequadamente aplicável à educação é a que desenvolve teoria que pode ser comprovada pelos professores. É nesse contexto que se faz necessário projetar o professor como pesquisador de sua própria prática, movido por indagação sistemática, tornando a sua própria ação docente uma investigação hipotética e experimental.

Diante das dificuldades de os professores constituírem-se como pesquisadores, porque não sabem o que fazem, Stenhouse contrapõe afirmando que "a capacidade de investigar do professor depende de estratégias de auto-observação semelhante a um artista que consciente do que faz, está sempre alerta para o seu próprio trabalho, o que lhe permite utilizar-se a si como instrumento de investigação" (apud DICKEL, 2001, p. 57).

A tese defendida aqui segue os passos apontados por Stenhouse e consiste na defesa em formar um professor que não abdica do aprender porque a vivência da curiosidade, da vontade de ver/fazer 
coisas novas e realidades que não estão dadas, é a possibilidade que esse profissional tem de contagiar o aluno. É um professor que, capaz de se indignar sobre as contradições que surgem no exercício da docência, agrega outros elementos na tarefa de suportar o mundo e de guiá-los por uma história que não negue a existência humana, um professor que se capacita para contribuir com a elaboração de uma teoria pedagógica que aposte na atividade docente como produtora de possibilidades capazes de projetar aprendizagens diferentes, altamente importantes para o futuro profissional.

Muitas vezes os professores são contratados para a atividade de docência universitária sem terem consciência de que o processo de ensino e de aprendizagem não é uma ação mecânica. Seu prestígio como docente, muitas vezes, vem da pesquisa ou da titulação acadêmica (mestrado e doutorado). Mas nem sempre o bom pesquisador é um bom professor. São inúmeras as situações em que "pesquisadores de excelência" têm dificuldades de ministrar boas aulas, não conseguem estabelecer relações pedagógicas que promovam a aprendizagem dos alunos, não possuem habilidades didáticas para "traduzir" suas pesquisas em conteúdos pedagógicos de suas aulas. Tais investigadores, não raramente, não são capazes de realizar uma autocrítica, justificando suas ações em seu status como reconhecidos pesquisadores. Sobre isso, o fato de não problematizarem sua própria ação docente, geralmente os torna culpados pelo fracasso escolar que acontece com muita frequência.

Está disposto na legislação educacional brasileira que a atividade do professor universitário deverá se organizar sobre o tripé ensino, pesquisa e extensão. Como é atribuição da autonomia das instituições administrar a distribuição das atividades do professor, muitas vezes acontece um processo de marginalização de algumas dessas atividades e de detrimento de outras. Cria-se, assim, uma divisão dos docentes universitários entre os que se dedicam prioritariamente à pesquisa, outros à extensão e outros somente ao ensino. Essa divisão dificulta e "empobrece" as três atividades, pois sua realização deveria acontecer num processo de "indissociabilidade", conforme indica a própria legislação. Muitos professores universitários almejam ardentemente se tornarem pesquisadores, com a clara intenção de se livrarem do "ônus" de ministrar aulas. Porém, não se pode esquecer que uma das atividades essenciais que caracterizam a atuação dos profissionais docentes da universidade é o ensino. Como nos diz Vera Lucia Bazzo (2007, p. 60):

\footnotetext{
Ser pesquisador e produtor de novos conhecimentos é de fato importante, principalmente porque essas atividades estão vinculadas à ocupação do professor universitário em qualquer lugar do mundo, porém não substituem, nem se igualam - seja em objetivos, habilidades, mentalidade, atuações específicas, seja em conhecimentos necessários ao exercício da investigação - ao trabalho docente.
}

É possível um ensino de boa qualidade sem pesquisa? A articulação ensino-pesquisa constitui condição necessária para que o processo de ensino e aprendizagem atinja um padrão de excelência? O êxito de um professor depende dele ser obrigatoriamente um pesquisador? A pesquisa pode vir a ser um entrave para a boa docência? Embora difícil, é possível atingir um ensino de boa qualidade sem que o professor seja um pesquisador no sentido convencional. No entanto, é necessário que tenha um "sólido conhecimento de sua área" e possua uma "capacitação invejável de comunicação" com seus alunos. Mas tanto o "sólido conhecimento" quanto a "capacitação invejável de comunicação" são qualidades provenientes de processos de pesquisa.

Quando for superada a máxima do senso comum que diz que "o bom profissional garante o bom professor", talvez possa surgir a compreensão de que o bom professor seria o profissional que detém conhecimento sólido e atualizado em sua área específica - o cientista, e também o mestre. Esse professor participaria tanto da produção na área educacional com vistas ao domínio dos conhecimentos e técnicas necessárias à construção de sua profissionalidade docente, quanto da pesquisa que garante a permanente atualização em seu campo específico.

Nem todo professor, por ser reflexivo, é também pesquisador, embora a recíproca seja verdadeira. A atividade de pesquisa implica uma posição reflexiva, e ambas, a reflexão e a pesquisa, devem envolver um componente crítico. $O$ fato de participar de um trabalho de pesquisa pode permitir a uma pessoa sentir-se ligada a essa atividade, e declarar-se como tal. Segundo Ludke (2010, p. 35), "a expressão 'fazer pesquisa' indica uma responsabilidade maior sobre essa atividade que, se for realizada com regularidade e autonomia, pode então conduzir um indivíduo ao status de pesquisador, com distinção e o reconhecimento correspondentes, sobretudo na academia". 
A pesquisa e a formação podem representar componentes estratégicos para o desenvolvimento profissional do docente, que pode aceitar desvios ou sacrifícios de seus objetivos precípuos como professor da educação básica. A universidade e os cursos de pós-graduação, com seus valores e sua cultura próprios, podem desempenhar um papel fundamental nesse processo, legitimando um perfil de pesquisador mais próximo ao modelo acadêmico, ou mesmo de acordo com o trabalho de pesquisa que também pode se dar nas práticas escolares da educação básica, o que parece ainda ser um desafio para os estudiosos do tema.

\section{CONSIDERAÇÕES FINAIS}

Acredita-se que a formação do educador seja o fator determinante para que haja melhorias no processo ensino-aprendizagem, e na formação do cidadão consciente e emancipado. Não se pode atribuir à educação formal toda a responsabilidade da mudança e da transformação social, pois a estrutura social impõe muitas limitações à ação educacional. Entende-se o professor universitário como um intelectual imerso numa realidade contraditória e de dependência, da qual sofre influências.

Por outro lado, entende-se que ele pode exercer influências para a mudança desse contexto com seu papel de formador político, pois o egresso de cursos de licenciatura desempenha docência nos mais variados ambientes das escolas públicas e privadas, nos quais ou reproduz as relações de desigualdade social, ou tenta transformá-las por meio de novos paradigmas de valores, ideais, propostas e visões de mundo. A qualidade do ensino vincula-se diretamente à formação do educador na universidade. Dessa forma, salienta-se que a contribuição dos professores para a formação dos cidadãos exige o desenvolvimento de habilidades e competências que possibilitem o estabelecimento de relações entre o conhecimento construído e a realidade histórico-social vigente.

No plano organizativo, a estrutura do ensino nos níveis de graduação e pós-graduação estabelece uma diferenciação de objetivos: o preparo para o exercício profissional e a formação da nova geração, ou ainda, o preparo do pesquisador, do profissional altamente qualificado e do professor de ensino superior. Entre esses níveis, independentemente dos objetivos aos quais se destinam, existe uma vinculação de conhecimento basilar que reflete na vinculação ensino-pesquisa. Outro ponto a destacar é o da existência de uma vinculação entre metodologia do ensino e metodologia da pesquisa.

As pessoas tendem a adotar uma postura em face da verdade, tendem a entendê-la de uma maneira dada. Não pode existir, portanto, um distanciamento substancial entre compreensão da verdade presente no processo de produção do conhecimento e a concepção presente na disseminação pelo ensino. O ponto crucial é o acesso a conhecimentos sistematizados que a pós-graduação traz consigo, conhecimentos esses que têm a pesquisa em sua gênese. Nessa etapa do processo de formação, o professor de ensino superior não tem acesso só a pesquisas, mas também ao conhecimento sistematizado de como desenvolvê-la em sua área específica.

Por fim, acredita-se na necessidade de discutir o significado de ser professor pesquisador, além das razões da produção de conhecimento na formação humana, em especial, em contextos sociais permeados de manipulação e de ligeireza científica. Em momentos em que o capitalismo produz crescente degradação da vida humana, verifica-se uma tendência de desqualificação teórica nas pesquisas na área da educação, com gravíssimas implicações políticas e éticas, além das epistemológicas.

\section{REFERÊNCIAS}

ABREU, Maria Célia Teixeira Azevedo de. O professor universitário em aula: prática e princípios teóricos. 9. ed. São Paulo: MG, 1990.

BAZZO, Vera Lúcia. Dilemas da profissionalidade docente na Educação Superior: entre o cientista e o mestre. In: FRANCO, Maria Estela Dal Pai; KRAHE, Elizabeth D. (Orgs.). Pedagogia universitária e áreas do conhecimento. Porto Alegre: EDIPUCRS, 2007. p. 57-72.

DICKEL, Adriana. Que sentido tem em se falar em professor-pesquisador no contexto atual? Contribuições para o debate. In: GERALDI, Corinta Maria Grisolia et al. (Orgs.). Cartografias do trabalho docente: professor(a)-pesquisador(a). Campinas: Mercado de Letras, 2001. p. 33-71. 
FÁVERO, Altair Alberto; TONIETO, Carina. Educar o educador: reflexões sobre formação docente. Campinas: Mercado de Letras, 2010.

FRANCO, Maria Estela Dal Pai. Comunidade de conhecimentos, pesquisa e formação do professor do ensino superior. In: MOROSINI, Marília Costa (Org.). Professor do ensino superior: identidade, docência e formação. Brasília: Instituto Nacional de Estudos e Pesquisas Educacionais, 2000. p. 61-73.

GIROUX, Henry. Professores como intelectuais transformadores. In: GIROUX, Henry. Os professores como intelectuais: rumo a uma pedagogia crítica da aprendizagem. Porto Alegre: Artes Médicas, 2007, p. 157-164.

LEITE, Denise et al. A avaliação institucional e os desafios da formação do docente na universidade pósmoderna. In: MASETTO, Marcos (Org.). Docência na universidade. 9. ed. Campinas: Papirus, 2008. p. 39-56.

LUDKE, Menga. A complexa relação entre o professor e a pesquisa. In: ANDRÉ, Marli (Org.). O papel da pesquisa na formação e na prática dos professores. 10. ed. Campinas, SP: Papirus, 2010. p. 27-54.

MASETTO, Marcos. Docência universitária: repensando a aula. In: TEODORO, Antonio; VASCONCELLOS, Maria Lucia (Orgs.). Ensinar e aprender no ensino superior: por uma epistemologia da curiosidade na formação universitária. 2. ed. São Paulo: Cortez/ Mackenzie, 2005. p. 79-108.

MASETTO, Marcos. Professor Universitário: um profissional da educação na atividade docente. In: MASETTO, Marcos T. (Org.). Docência na Universidade. 9. ed. São Paulo: Papirus, 1998, pp.9-25.

MISUKAMI, Maria da Graça Nicoletti. Ensino: as abordagens do processo. São Paulo: EPU, 1986.

MORAES, Irany Novah. Perfil da Universidade. São Paulo: Pioneira, 1986.

MOROSINI, Marília Costa. O professor do ensino superior na sociedade contemporânea. In: ENRICONE, Délcia (Org.). A docência na educação superior: sete olhares. 2. ed. Porto Alegre: EDIPUCRS, 2008. p. 95-110.

. Docência universitária e os desafios da realidade nacional. In: MOROSINI, Marília Costa (Org.). Professor do ensino superior: identidade, docência e formação. Brasília: Instituto Nacional de Estudos e Pesquisas Educacionais, 2000. p. 11-20.

PÉREZ GÓMEZ, Angel. "O pensamento prático do professor: a formação do professor como profissional reflexivo", in: NÓVOA, Antonio (org.). Os professores e sua formação. Lisboa: Publicações Dom Quixote, 1995, pp. 93-114.

SARTORI, Jerônimo. A ação docente do professor dos cursos de licenciatura da Universidade de Passo Fundo. Passo Fundo: Ediupf, 1998.

SOUSA, Oscar de. Aprender e ensinar: significados e mediações. In: TEODORO, Antonio; VASCONCELLOS, Maria Lucia (Orgs.). Ensinar e aprender no ensino superior: por uma epistemologia da curiosidade na formação universitária. 2. ed. São Paulo: Cortez/ Mackenzie, 2005. p. 35-60.

STENHOUSE, Laurence. La investigación y desarollo del curiculum. Madrid: Marota, 1984.

TAUCHEN, Gionara; FÁVERO, Altair Alberto. O princípio da indissociabilidade universitária: dificuldades e possibilidades de articulação. Revista Linhas Críticas, Brasília, DF, v. 17, n. 33, p. 403-419, maio/ ago. 2011

ZABALZA, Miguel A. O ensino universitário: seu cenário e seus protagonistas. Porto Alegre: Artmed, 2004.

Artigo recebido em 09/06/2013

Aprovado em 09/10/2013 